Case Report

\title{
"Hidden" fistula in a newborn with imperforate anus
}

\author{
Abstract \\ We present the case of a male newborn with imperforate anus and no visible fistula. After \\ careful physical examination a perineal fistula was found and proper surgical treatment was \\ performed.
}

Keywords: imperforate anus, anorectal malformation, perineal fistula
Volume I Issue 6 - 2014

\author{
Bruno Martinez Leo,Victor Alarcon \\ Quezada, Carlos Baeza Herrera \\ Hospital Pediatrico Moctezuma, Secretaria de Salud del Distrito \\ Federal, Mexico
}

\begin{abstract}
Correspondence: Bruno Martinez Leo,Attending Pediatric Surgeon, Hospital Pediatrico Moctezuma, Secretaria de Salud del Distrito Federal, Oriente I58 \#189, Moctezuma 2a seccion Del Venustiano Carranza, D.F. CP I5I00, Mexico, Tel 526000000000 , Email Bruno.martinezleo@gmail.com
\end{abstract}

Received: October 30, 2014 | Published: November 06, 2014

\section{Introduction}

Imperforate anus (anorectal malformation) is a frequent malformation found in neonates. One in 1,500 to 5,000 newborns per year will be born with an anorectal malformation. ${ }^{1}$ Primary care physicians and care givers should be knowledgeable about the different clinical presentations of these malformations in order to provide proper and prompt care.

\section{Case presentation}

An 18-hour male newborn was sent to our institution for evaluation of imperforate anus and "no visible fistula" and colostomy creation. Physical exam showed no cardio respiratory or neurological compromise. He had imperforate anus, descended testicles, normal penis and perineum with a rather normal raphe with no visible fistula or opening (Figure 1). After a more thorough examination of the perineum a fistulous tract extending from the anal dimple to the scrotum became very conspicuous when careful positive pressure was applied to the baby's abdomen. This made evident the passage of meconium from the rectum into the fistula extending to the scrotum (Figure 2). Afterwards the decision was made to treat the baby with an anoplasty without the need for opening a colostomy. The patient had an uneventful postoperative course and was discharged 7 days later.

\section{Discussion}

Imperforate anus or, more properly called, Anorectal Malformations occur when an arrest in the development of the anal, genital and urinary components during the embryonary life. ${ }^{2}$ This produces a spectrum of malformations at any of those levels with or without abnormal communications between those structures called fistulas. The most important and clear manifestation is an imperforate anus at birth. Male patients with anorectal malformations may present with no external anatomic manifestation of a fistula connecting the blind rectum to any portion of the urinary tract between the bladder neck and the urethra in its prostatic or bulbar portions. ${ }^{3}$ Some of them have no fistula connecting the rectum to any other structure. On the other side some other patients present with a fistulous opening at the perineum or, as in our patient, a very inconspicuous fistulous tract from the rectum into the superficial skin. The initial management of the newborn with anorectal malformations includes the decision of opening a colostomy in male patients with no visible fistula and suggests primary repair for those with perineal fistulas, depending on surgeon's experience and resources available. ${ }^{4}$ If the patient is not treated on a timely fashion, serious clinical consequences such as dehydration from vomiting, electrolyte disturbances, acute abdomen and intestinal perforation may arise. ${ }^{5}$

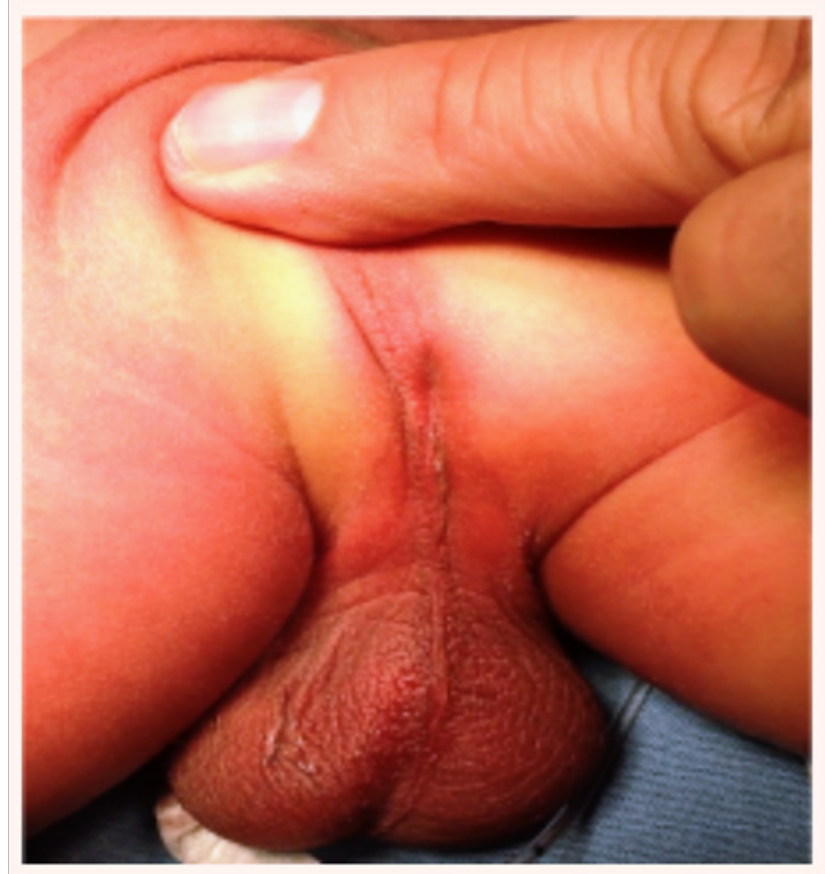

Figure I Picture of perineum of the patient, note imperforate anus and no visible fistula.

Physical exam is paramount in determining the presence or absence of a perineal fistula in a male patient with anorectal malformation. The healthcare provider dealing with newborns must be related to the clinical presentation of anorectal malformations in order to achieve a proper and timely referral.

\section{Acknowledgements}

None.

\section{Conflicts of Interest}

There is no conflict of interest. 


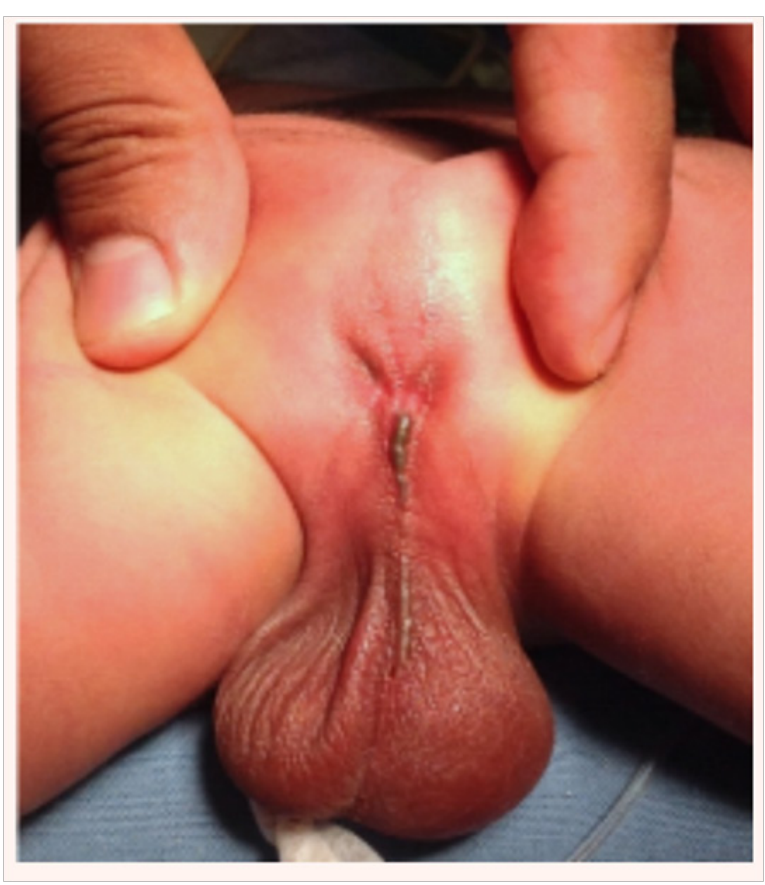

\section{Funding}

None.

\section{References}

1. Cuschieri A. Descriptive epidemiology of isolated anal anomalies: a survey of 4.6 million births in Europe. Am J Med Genet. 2001;103(3): $207-215$.

2. Kluth D, Fiegel HC, Metzger R. Embryology of the hindgut. Semin Pediatr Surg. 2011;20(3):152-160.

3. Bischoff A, Levitt MA, Pena A. Update on the management of anorectal malformations. Pediatr Surg Int. 2013;29(9): 899- 904.

4. Wilkins S, Pena A. The role of colostomy in the management of anorectal malformations. Pediatr Surg Int. 1988;3:105- 109.

5. Chan KW, Lee KH, Wong YS, et al. Bowel perforation in newborn with anorectal malformation and no fistula at presentation. J Pediatr Surg. 2014;49(3): 390- 394.

Figure 2 Picture of perineum of the patient after gentle abdominal pressure was applied. Note the filling of meconium into a fistulous tract extending into the skin of the scrotum. 